\title{
Growth promotion of some lactic acid bacteria by crude extract of Spirogyra sp., Cladophora sp., Caulerpa lentillifera and Caulerpa corynephora
}

\author{
${ }^{1,{ }^{*}}$ Chadseesuwan, U., ${ }^{2}$ Puthong, S. and ${ }^{1}$ Deetae, P. \\ ${ }^{1}$ Faculty of Food Industry, King Mongkut's Institute of Technology Ladkrabang, Bangkok 10520, Thailand \\ ${ }^{2}$ Institute of Biotechnology and Genetic Engineering, Chulalongkorn University, Bangkok 10330, Thailand
}

\section{Article history:}

Received: 23 July 2020

Received in revised form: 9

November 2020

Accepted: 10 January 2021

Available Online: 17 January 2021

\section{Keywords:}

Caulerpa corynephora, Caulerpa lentillifera, Cladophora sp., Spirogyra sp., Prebiotic

DOI:

https://doi.org/10.26656/fr.2017.4(S4).011

\begin{abstract}
The aim of this research was to evaluate the growth promotion of two freshwater macroalgae (Spirogyra sp., Cladophora sp.) and two saltwater macroalgae (Caulerpa lentillifera and Caulerpa corynephora) crude extracts to some lactic acid bacteria using in vitro fermentation. Total soluble carbohydrates of macroalgae were obtained after extraction with $75^{\circ} \mathrm{C}$ of water for $1 \mathrm{hr}$. The concentration of total sugar and reducing sugar were 0.764 and $0.197 \mathrm{mg} / \mathrm{g}$ in Spirogyra sp., 0.368 and $0.082 \mathrm{mg} / \mathrm{g}$ in Cladophora sp., 0.484 and $0.055 \mathrm{mg} / \mathrm{g}$ in C. lentillifera, and 0.253 and $0.037 \mathrm{mg} / \mathrm{g}$ in C. corynephora, respectively. Degree of polymerization (DP) that refers to the size of oligosaccharide, were $3.8,4.5,8.8$ and 6.8 , respectively. The prebiotic activity was assessed by the change of the bacterial population. Crude extracts from macroalgae were tested for growth stimulation effect on lactic acid bacteria, Lactobacillus plantarum TISTR862 and Escherichia coli TISTR073. Results demonstrated that the population of L. plantarum TISTR862 and E. coli TISTR073 were higher in crude extracts from freshwater than saltwater macroalgae. The prebiotic activity score was calculated based on the change of growth in probiotic and pathogen after $24 \mathrm{hrs}$ of incubation time. The highest score was obtained from $C$. corynephora extracts (1.10) follow by $C$. lentillifera extracts (0.77), Cladophora sp. extracts (0.173) and Spirogyra sp. extracts (0.07). In comparison with commercial culture (Lactobacillus casei, Lactobacillus lactis, Streptococcus thermophilus and Bifidobacterium), the addition of $3.5 \%$ C. lentillifera extracts resulted as prebiotic activity score value as $3.5 \%$ FOS. Preliminary study demonstrated that crude extract of $C$. lentillifera could be a prebiotic substance.
\end{abstract}

\section{Introduction}

The interest in probiotics and prebiotics are increasing due to the important role played in human nutrition. Probiotic are defined as live microorganisms that confer a health benefit on the host (Cao et al., 2020) that can protect humans from diseases, modulated the immune system and have anticancer properties (Konuray and Erginkaya, 2018). Prebiotics are defined as nondigestible food ingredients that beneficially affect host health by selectively stimulating the growth and/or activity of one or a limited number of bacterial in the colon (Gibson and Roberfroid, 1995).

Spirogyra sp., Tao in Thai common name, is the freshwater macroalgae in northern Thailand (Figure 1a). Tao was found in stagnant water and reaching abundance during hot dry and before entering the rainy season. Cladophora sp. is known as Kai, is also freshwater macroalgae (Figure 1b). It is abundant in Nan province, the Northern part of Thailand (Khuantrairong and Traichaiyaporn., 2011). Their identity character is the light rough. Spirogyra sp. and Cladophora sp. are freshwater macroalgae in Division in Chlorophyta (Sakulpong et al., 2015). C. corynephora or Konnok is the saltwater macroalgae and found in southern of Thailand (Figure 1c). C. corynephora is an edible and treasure house of novel healthy food ingredients and biological active compounds (Fithriani, 2015). Also $C$. lentillifera shown in Figure 1d, also known as Sea Grapes, are saltwater macroalgae eaten raw as salad and cultivated in different parts of the world, particularly in the Indo-Pacific region (Yap et al., 2019). Macroalgae is a source of food for human and feed for animal. Many kinds of research were focused on the nutritional value of macroalgae such as protein, lipid, fiber and carbohydrate. From nutrition point, macroalgae are rich 
in carbohydrates. Polysaccharides are polymeric molecules of carbohydrates. Nowadays, the interest in the development of prebiotics has been focused on the use of nondigestible oligosaccharides and polysaccharides which cannot be digested but are readily fermented by colonic bacteria (Zhang et al., 2003). Many polysaccharides from various sources have display prebiotic properties both in vitro and in vivo. There are few studies on the use of macroalgae as prebiotics substances. So, the growth promotion of some lactic acid bacteria by two freshwater macroalgae (Spirogyra sp., Cladophora sp.) and two saltwater macroalgae (C. lentillifera and C. corynephora) crude extracts using in vitro fermentation were evaluated. (a)

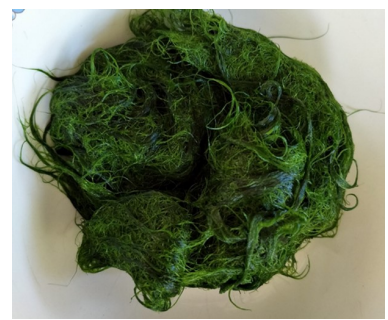

(c)

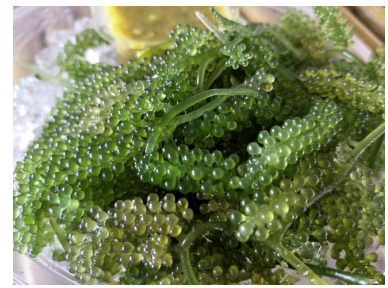

(b)

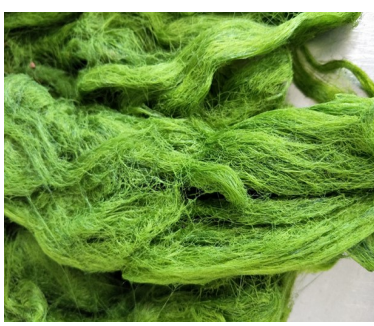

(d)

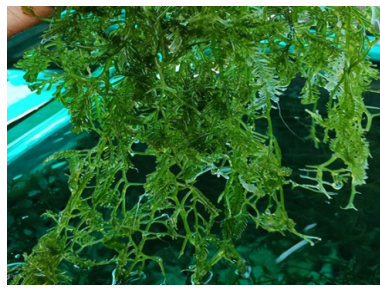

Figure 1. Freshwater and saltwater macroalgae; freshwater macroalgae (a) Spirogyra sp. or "Tao" (b) Cladophora sp. or "Kai", (c) Caulerpa lentillifera or "Sea Grape" and (d) Caulerpa corynephora or "Konnok".

\section{Materials and methods}

\subsection{Chemicals, reagents and microorganisms}

De Man, Rogosa and Sharpe Agar or MRS agar (HIMedia, India), Eosin Methylene Blue Agar or EMB agar (HIMedia, India), M17 agar (HIMedia, India) and Bifidobacterium agar (HIMedia, India) were used in the isolation and selective enumeration of Lactobacillus species, E. coli, Streptococcus sp. and Bifidobacterium, respectively.

Lactic acid bacteria used in this research was $L$. plantarum TISTR082 and enteric strain used were E. coli TISTR073 were purchased from the Thailand Institute of Scientific and Technological Research (TISTR), Pathumthani Province, Thailand. Commercial culture of probiotics (L. acidophilus, L. casei, S. thermophiles and $B$. animalis) was purchased from Sacco, Italy.

\subsection{Materials}

Freshwater macroalgae (Spirogyra sp., Cladophora sp.) and two saltwater macroalgae (C. lentillifera and $C$. corynephora) were studied. Spirogyra sp., Cladophora sp. were collected from Phare and Nan Province, Thailand, $C$. lentillifera and $C$. corynephora were collected from Phetchaburi and Krabi Province, Thailand, respectively. All impurities were removed by the water. Macroalgae were dried at $70^{\circ} \mathrm{C}$ for $12 \mathrm{hrs}$.

\subsection{Extraction}

The samples of macroalgae were air-dried and grounded. Crude macroalgae carbohydrates were extracted with $70^{\circ} \mathrm{C}$ of water at the ratio of $1: 10$ (powdered macroalgae: distilled water) and shaken with rotary shaker for $1 \mathrm{hr}$. Subsequently, crude extracts were filtrated, evaporated and concentrated by the rotary evaporator at $45^{\circ} \mathrm{C}$. Finally, the resultant samples were stored at $-20^{\circ} \mathrm{C}$ until use.

\subsection{Analysis of the amount of carbohydrate}

The total sugar and reducing sugar in each crude extracts were determined by using Phenol-Sulphuric method and DNS method, respectively (DuBois et al., 1956; Miller 1972; Li et al., 2017). An average degree of polymerization (DP) was calculated as the value of the amount of total sugar divided by the amount of reducing sugar (Wongputtisin et al., 2015).

\subsection{In vitro prebiotic activity}

\subsubsection{Prebiotic property study by single culture test}

The crude extracts of macroalgae were added as a carbon source at a concentration of $3.5 \%(\mathrm{w} / \mathrm{v})$ in the basal medium $\left(\mathrm{K}_{2} \mathrm{HPO}_{4} 0.3, \mathrm{KH}_{2} \mathrm{PO}_{4} 0.1\right.$, yeast extract 1.0, peptone 1.0, $\mathrm{MgSO}_{4} 0.2$ and $\left(\mathrm{NH}_{4}\right)_{2} \mathrm{SO}_{4} 2.5 \mathrm{~g} / \mathrm{L}, \mathrm{pH}$ 7.0). The media were sterilized. The individual tubes were inoculated with approximately $10^{6} \mathrm{CFU}$ of 12 hourold inoculum of $L$. plantarum and E. coli. The cultivations were incubated at $37^{\circ} \mathrm{C}$ for $60 \mathrm{hrs}$ in anaerobic condition. Samples of the fermentation broth were withdrawn from each tube at $0,12,24,36,48$ and $60 \mathrm{hrs}$ for cell counting. Sampling of viable cell enumeration was performed on MRS agar and EMB agar for L. plantarum and E. coli, respectively. Moreover, the growth of tested strains in basal medium with glucose and without carbon source was also studied as a control treatment. Data were reported as the ratios of the log $\mathrm{CFU} / \mathrm{mL}$ counts of the bacteria.

\subsubsection{Prebiotic property study by commercial culture test}

The evaluation growth promotion of crude macroalgae extracts was performed as described above. Varying concentration of each carbon source ranging from $1.5-3.5 \% \mathrm{w} / \mathrm{v}$ was tested. Commercial cultures were used in the experiment and represented as probiotic. This commercial culture was mixed with $L$. 
casei, L. lactis, S. thermophiles and B. animalis. FOS was used as a positive control due to its well-established prebiotic properties, whereas basal medium without carbon source was used as a negative control. Inoculum of commercial culture was transferred to a sterilized basal medium. The cultivations were conducted at $37^{\circ} \mathrm{C}$ for $24 \mathrm{hrs}$ in anaerobic condition. Samples of the fermentation broth were withdrawn at 0 and $24 \mathrm{hrs}$ for cell counting. Sampling of viable cell enumeration was performed on MRS agar, M17 agar, Bifidobacterium agar and EMB agar for $L$. casei, L. lactis, $S$. thermophiles, B. animalis and E. coli, respectively.

\subsection{Prebiotic activity score}

According to Hueber et al. (2007), the prebiotic activity score was calculated using the following equation:

Prebiotic activity score $=\{$ (probiotic $\log \mathrm{CFU} / \mathrm{mL}$ on the prebiotic at $24 \mathrm{hrs}-$ probiotic $\log \mathrm{CFU} / \mathrm{mL}$ on the prebiotic at $0 \mathrm{hr}$ ) / (probiotic $\log \mathrm{CFU} / \mathrm{mL}$ on glucose at $24 \mathrm{hrs}-$ probiotic $\log \mathrm{CFU} / \mathrm{mL}$ on glucose at $0 \mathrm{hr})\}-$ $\{$ (enteric $\log \mathrm{CFU} / \mathrm{mL}$ on the prebiotic at $24 \mathrm{hrs}$ - enteric $\log \mathrm{CFU} / \mathrm{mL}$ on the prebiotic at $0 \mathrm{hr}$ ) / (enteric $\log \mathrm{CFU} /$ $\mathrm{mL}$ on glucose at $24 \mathrm{hrs}-$ enteric $\log \mathrm{CFU} / \mathrm{mL}$ on glucose at $0 \mathrm{hr}$ ) $\}$.

By definition, substrates with a high prebiotic activity score support good growth of the probiotic bacteria, with viable cell $(\mathrm{CFU} / \mathrm{mL})$ comparable with that when grown on glucose.

\subsection{Statistical analysis}

Descriptive results are presented as mean plus or minus standard deviation. ANOVA was used to assess the significance of descriptive data. $P$ values $<0.05$ were considered significant. Dunnett's was used to identify the group that were similar with respect to the mean.

\section{Results and discussion}

3.1 The amount of sugar of freshwater macroalgae and saltwater macroalgae

The concentration of total sugar and reducing sugar were 0.764 and $0.197 \mathrm{mg} / \mathrm{g}$ in Spirogyra sp., 0.367 and
$0.082 \mathrm{mg} / \mathrm{g}$ in Cladophora sp., 0.484 and $0.055 \mathrm{mg} / \mathrm{g}$ in C. lentillifera, and 0.253 and $0.037 \mathrm{mg} / \mathrm{g}$ in $C$. corynephora, respectively. DP of sample extracts were $3.8,4.5,8.8$ and 6.8 , respectively (Table 1). DP of 2-9 or sometimes 8-20 monomers are classified as oligosaccharides that correspond to the prebiotic definition. Moreover, prebiotics is thought to be nondigestible by the human or animal digestive enzyme (Saad et al., 2013). These oligosaccharides seem easier for fermenting by gut microbiota (de Jesus Raposo et al., 2016).

Table 1. Total sugar, reducing sugar concentration and DP of two freshwater macroalgae and two saltwater macroalgae.

\begin{tabular}{lccc}
\hline $\begin{array}{c}\text { Aqueous extracts of } \\
\text { macroalgae }\end{array}$ & $\begin{array}{c}\text { Total sugar } \\
(\mathrm{mg} / \mathrm{g})\end{array}$ & $\begin{array}{c}\text { Reducing sugar } \\
(\mathrm{mg} / \mathrm{g})\end{array}$ & DP \\
\hline $\begin{array}{l}\text { Spirogyra } \text { sp. (Tao) } \\
\text { Cladophora } \text { sp. (Kai) }\end{array}$ & 0.764 & 0.197 & 3.8 \\
$\begin{array}{l}\text { Caulerpa lentillifera } \\
\text { (Sea Grape) }\end{array}$ & 0.367 & 0.082 & 4.5 \\
$\begin{array}{l}\text { Caulerpa corynephora } \\
\text { (Konnok) }\end{array}$ & 0.253 & 0.055 & 8.8 \\
\hline
\end{tabular}

\subsection{Growth of Lactobacillus plantarum and Escherichia coli on macroalgae extracts}

Crude Spirogyra sp., Cladophora sp., C. lentillifera and $C$. corynephora extracts were selected as carbon source for in vitro fermentation study. In this experiment, L. plantarum TISTR 862 and E. coli TISTR073 were represented as lactic acid bacteria and enteric strain. The populations of tested strain in basal medium added with different carbon sources from macroalgae were shown in Tables 2-3. Basal medium without carbon source and with glucose served as blank and control group, respectively. Results demonstrated that the population of L. plantarum and E. coli were higher in sample extracts from freshwater than saltwater macroalgae. In contrast, the population of E. coli was not promoted in basal medium added with crude extracts from saltwater macroalgae. Growth of enteric strain (E. coli) on $C$. corynephora extracts and $C$. lentillifera extracts were lower than growth on Cladophora sp. extracts, Spirogyra sp. and glucose as carbon sources in basal medium. It might indicate that crude extracts from saltwater macroalgae were utilized less well by enteric strain than

Table 2. Growth of single tested strains of L. plantarum in the basal medium added with different carbon source when incubating for $60 \mathrm{hrs}$.

\begin{tabular}{|c|c|c|c|c|c|c|}
\hline \multirow{2}{*}{ Carbon sources } & \multicolumn{6}{|c|}{ L. plantarum $(\log \mathrm{CFU} / \mathrm{mL})$} \\
\hline & $0 \mathrm{hrs}$ & $12 \mathrm{hrs}$ & $24 \mathrm{hrs}$ & $36 \mathrm{hrs}$ & $48 \mathrm{hrs}$ & $60 \mathrm{hrs}$ \\
\hline Non-carbon & $5.63 \pm 0.07$ & $5.78 \pm 0.06$ & $6.27 \pm 0.06$ & $5.88 \pm 0.01$ & $5.70 \pm 0.05$ & $5.51 \pm 0.03$ \\
\hline Glucose & $5.76 \pm 0.02$ & $6.13 \pm 0.01$ & $7.12 \pm 0.03$ & $7.17 \pm 0.05$ & $7.12 \pm 0.03$ & $6.70 \pm 0.21$ \\
\hline Spirogyra sp. or Tao & $5.82 \pm 0.01$ & $7.30 \pm 0.08$ & $7.45 \pm 0.10$ & $7.38 \pm 0.08$ & $7.16 \pm 0.67$ & $7.07 \pm 0.27$ \\
\hline Cladophora sp. or Kai & $6.04 \pm 0.03$ & $7.42 \pm 0.21$ & $7.72 \pm 0.21$ & $7.38 \pm 0.21$ & $7.37 \pm 0.06$ & $6.58 \pm 0.06$ \\
\hline Caulerpa lentillifera or Sea Grape & $5.90 \pm 0.03$ & $5.97 \pm 0.01$ & $7.14 \pm 0.03$ & $6.96 \pm 0.01$ & $6.77 \pm 0.05$ & $6.66 \pm 0.07$ \\
\hline Caulerpa corynephora or Konnok & $5.70 \pm 0.07$ & $5.83 \pm 0.12$ & $7.25 \pm 0.07$ & $7.32 \pm 0.01$ & $7.05 \pm 0.05$ & $6.89 \pm 0.07$ \\
\hline
\end{tabular}


Table 3. Growth of single tested strains of $E$. coli in the basal medium added with different carbon source when incubating for $60 \mathrm{hrs}$.

\begin{tabular}{lcccccc}
\hline \multirow{2}{*}{\multicolumn{1}{c}{ Carbon sources }} & \multicolumn{5}{c}{ E. coli $(\log$ CFU/mL) } \\
\cline { 2 - 7 } & $0 \mathrm{hrs}$ & $12 \mathrm{hrs}$ & $24 \mathrm{hrs}$ & $36 \mathrm{hrs}$ & $48 \mathrm{hrs}$ & $60 \mathrm{hrs}$ \\
\hline Non-carbon & $4.77 \pm 0.21$ & $6.90 \pm 0.15$ & $6.17 \pm 0.01$ & $6.16 \pm 0.08$ & $6.01 \pm 0.10$ & $5.96 \pm 0.08$ \\
Glucose & $4.90 \pm 0.02$ & $7.04 \pm 0.01$ & $6.99 \pm 0.05$ & $6.92 \pm 0.07$ & $6.80 \pm 0.03$ & $6.63 \pm 0.05$ \\
Spirogyra sp. or Tao & $4.77 \pm 0.03$ & $7.28 \pm 0.21$ & $7.12 \pm 0.21$ & $6.97 \pm 0.20$ & $6.96 \pm 0.15$ & $6.77 \pm 0.14$ \\
Cladophora sp. or Kai & $5.04 \pm 0.07$ & $7.43 \pm 0.01$ & $7.27 \pm 0.05$ & $7.19 \pm 0.07$ & $7.16 \pm 0.15$ & $7.11 \pm 0.14$ \\
Caulerpa lentillifera or Sea Grape & $4.77 \pm 0.10$ & $5.20 \pm 0.08$ & $5.07 \pm 0.06$ & $4.84 \pm 0.27$ & $4.69 \pm 0.05$ & $4.47 \pm 0.03$ \\
Caulerpa corynephora or Konnok & $4.69 \pm 0.06$ & $5.04 \pm 0.27$ & $4.77 \pm 0.29$ & $4.60 \pm 0.01$ & $4.60 \pm 0.06$ & $4.47 \pm 0.27$ \\
\hline
\end{tabular}

crude extracts from freshwater macroalgae. Lower cell counts at $24 \mathrm{hrs}$, may be the consequence of biochemical processes during later stages of growth and death of the bacteria (Shalini et al., 2017).

The prebiotic activity score was calculated based on the change of growth in probiotic and pathogen after 24 hrs of incubation time. Using the prebiotic activity score equation, the prebiotic activity score of a particular oligosaccharide can be determined relative to tested strain (Huebner et al., 2007). With the resulting score of activity, it was possible to compare prebiotic substances. From this research (Figure 2), the highest score was obtained from $C$. corynephora extracts (1.10) follow by C. lentillifera extracts (0.77), Cladophora sp. extracts (0.173) and Spirogyra sp. extracts (0.07). The higher the prebiotic activity score derived from the higher the relative growth of probiotic and lower the relative growth of pathogen (Rubel et al., 2014)

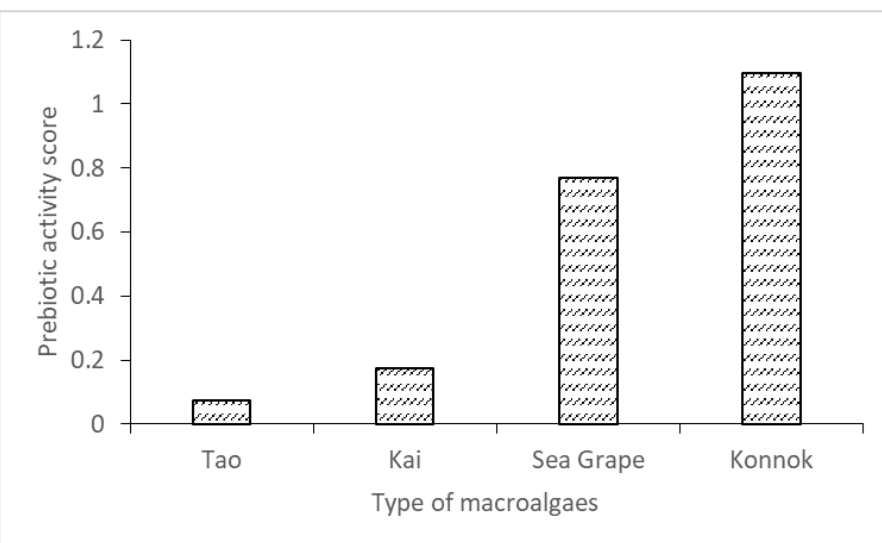

Figure 2. Prebiotic activity score of each macroalga

Saltwater macroalgae extracts could stimulate $L$. plantarum but could not stimulate $E$. coli. These were considered as a primary property of prebiotic substance. Saltwater macroalgae are rich in carbohydrates. The major component in green saltwater macroalgae are polysaccharide (25 - 75\% of the dry weight (DW)): of total dietary content (29-67\%) and soluble dietary fibre (17-24\%) (Charoensiddhi et al., 2017). The structural polysaccharides of saltwater macroalgae are sulphated polysaccharides, such as ulvans and sulphated galactans, xylans, mannan, while the main storage polysaccharide is starch (Charoensiddhi et al., 2017). According to Fithriani (2015), reported about Caulerpa sp. that richness in sulfated polysaccharides. The most polysaccharides from saltwater macroalgae can be considered as dietary fiber that is resistant to digestion by enzymes present in the human gastrointestinal tract, and selectively stimulate to the growth of beneficial gut bacteria (de Jesus Raposo et al., 2016). These effects may provide health benefits to humans through a prebiotic effect (O'Sullivan et al., 2010).

\subsection{Effect of Caulerpa lentillifera extracts on commercial culture}

C. lentillifera extracts were selected for the next study with commercial culture due to the high prebiotic activity score. The preliminary prebiotic effect of the selected crude extracts has been evaluated by comparison with FOS. The dosage used in the growth assay was determined by inoculating commercial culture and $E$. coli supplemented with varying concentration of FOS and $C$. lentillifera extracts. The tested prebiotic sample were analyzed at $1.5 \%, 2.5 \%$ and $3.5 \%(\mathrm{w} / \mathrm{v})$. Regarding the commercial cultures (L. casei, L. lactis, S. thermophiles and $B$. animalis), a stimulatory effect on the growth was observed for $24 \mathrm{hrs}$ using $C$. lentillifera extracts and FOS as carbon source. Viable cell numbers obtained were compared (Figure 3). The viable cell numbers of $S$. thermophiles reached a value of $4.5 \mathrm{log}$ $\mathrm{CFU} / \mathrm{mL}$ when used FOS as carbon source in basal medium. The increasing growth of L. casei, L. lactis, S. thermophiles and B. animalis in media added with FOS were higher than media added with $C$. lentillifera extracts. Prebiotic activity score of $C$. lentillifera extracts and FOS are represented in Figure 4. The prebiotic activity score of the pure prebiotic provides a reference level of prebiotic activity score. In the present study, the prebiotic activity score is indicative of selective use of carbon sources by 4 different probiotic strains in comparison with $E$. coli. The prebiotic activity score of $3.5 \%(\mathrm{w} / \mathrm{v})$ C. lentillifera extracts were 1.19, $0.55,0.72$ for Lactobacillus, $S$. thermophiles and B. animalis, respectively. FOS supported the growth of all the four probiotics strains suggesting its great prebiotic efficacy. C. lentillifera extracts had a lower score for all probiotic strains compared to FOS. The prebiotic activity score of $3.5 \%(\mathrm{w} / \mathrm{v})$ FOS for these cultures were 2.05, 0.69 and 0.87 , respectively. It might indicate that algae belonging 
to Division Chlorophyta, like Caulerpa, are rich in glucomannans, mannans, xylans, sulfated polysaccharides and pectins. Sulfated polysaccharides found in a wide range of algae exhibit their prebiotic effect by inhibiting the adhesion of pathogens (Kho et al., 2017). The results in the present study provide evidence for each microbial strain dependence on different carbon sources.

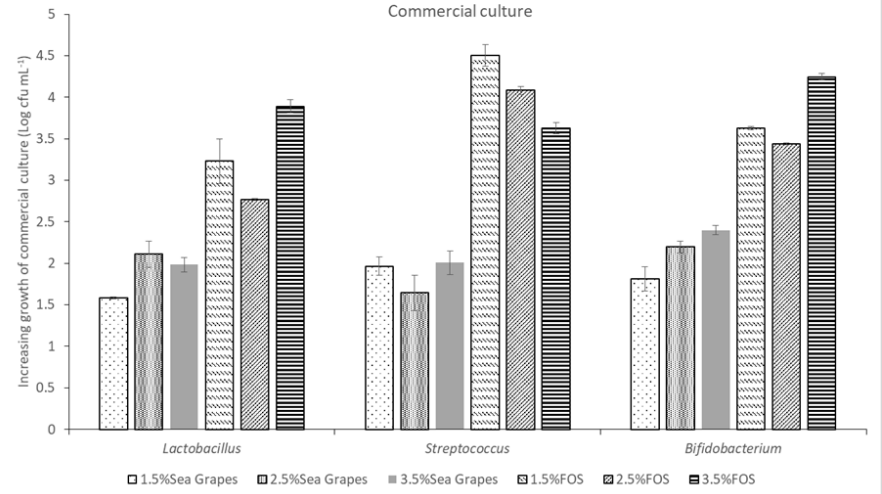

Figure 3. Increasing growth of commercial culture in basal medium added with different concentration of carbon sources.

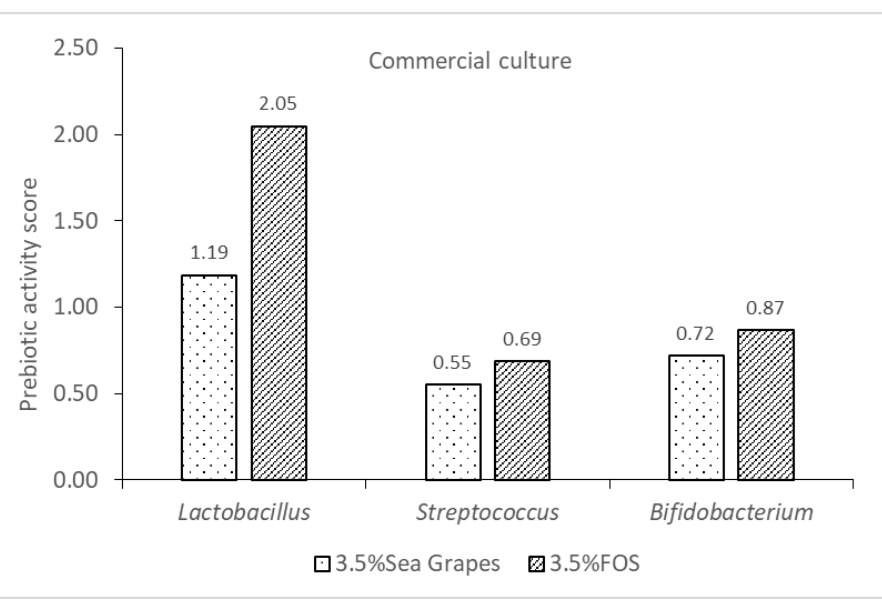

Figure 4. Prebiotic activity score of commercial cultures grown on basal medium supplemented with $3.5 \%(\mathrm{w} / \mathrm{v}) C$. lentillifera (sea grapes) extracts and 3.5\% (w/v) FOS.

\section{Conclusion}

The effectiveness of prebiotic substances depends on its ability to be selectively fermented by and to support the growth of specific targeted organisms (Huebner et al., 2007). But, this work was the preliminary study that shows the effect of crude macroalgae extracts on the growth of lactic acid bacteria. The results obtained here showed that crude saltwater macroalgae extracts could be considered to growth promotion for lactic acid bacteria. Therefore, the results of this work could support that the consumption of saltwater macroalgae could improve the health of consumers. However, additional research is required to establish the in vivo prebiotic capacity of saltwater macroalgae aiming its inclusion in functional food development.

\section{Conflict of interest}

The authors declare that they have no conflict of interest.

\section{Acknowledgement}

This study was financially supported by "The Thailand Research Fund" (grant number: RDG61T0054).

\section{References}

Cao, J., Yu, Z., Liu, W., Zhao, J., Zhang, H., Zhai, Q. and Chen, W. (2020). Probiotic characteristics of Bacillus coagulans and associated implications for human health and diseases. Journal of Functional Foods, 64, 103643. https://doi.org/10.1016/ j.jff.2019.103643

Charoensiddhi, S., Conlon, M.A., Franco, C.M.M. and Zhang, W. (2017). The development of seaweedderived bioactive compounds for use as prebiotics and nutraceuticals using enzyme technologies. Trends in Food Science and Technology, 70, 20-33. https://doi.org/10.1016/j.tifs.2017.10.002

de Jesus Raposo, M.F., de Morais, A.M.M.B. and de Morais, R.M.S.C. (2016). Emergent sources of prebiotics: Seaweeds and microalgae. Marine Drugs, 14(2), 1-27. https://doi.org/10.3390/md14020027

DuBois, M., Gilles, K.A., Hamilton, J.K., Rebers, P.A. and Smith, F. (1956). Colorimetric method for determination of sugars and related substances. Analytical Chemistry, 28, 350-356. https:// doi.org/10.1021/ac60111a017

Fithriani, D. (2015). Opportunities and challenges for developing Caulerpa racemosa as functional foods. The $1^{\text {st }}$ International Symposium on Aquatic Product Proceeding 2013, 1, 85-96. https://doi.org/10.18502/ kls.v1i0.90

Gibson, G.R. and Roberfroid, M.B. (1995). Dietary modulation of the human colonic microbiotia: introducing the concept of prebiotics. Journal of Nutrition, 125(6), 1401-1412. https:// doi.org/10.1093/jn/125.6.1401

Huebner, J., Wehling, R.L. and Hutkins, R.W. (2007). Functional activity of commercial prebiotics. International Dairy Journal, 17(7), 770-775. https:// doi.org/10.1016/j.idairyj.2006.10.006

Kho, M.J.N., Hernandez, R.B.B., Ladera, J.P.T., Khow, D.A.T., Lagura, V.A.M., Jacinto, J.A.C. and Medina, P.M.B. (2017). In vitro assessment of the prebiotic potential of Caulerpa lentillifera, Gracilaria arcuata and Sargassum polycystum on probiotic Lactobacillus species. International Journal of Biosciences, 10, 383-388. https://doi.org/10.12692/ $\mathrm{ijb} / 10.5 \cdot 382-388$ 
Khuantrairong, T. and Traichaiyaporn. (2011) The nutrition value of edible freshwater alga Cladophora sp. (Chlorophyta) grown under different phosphorus concentrations. International Journal of Agriculture and Biology, 13, 297-300.

Konuray, G. and Erginkaya, Z. (2018). Potential use of Bacillus coagulans in food industry. Journal of Foods, 7(6), 92. https://doi.org/10.3390/ foods 7060092

Li, Q., Loman, A.A., Coffman, A.M. and Ju, L-K. (2017). Soybean hull induced production of carbohydrates and protease among Aspergillus and their effectiveness in soy flour carbohydrate and protein separation. Journal of Biotechnology, 248, 35 -42. https://doi.org/10.1016/j.jbiotec.2017.03.013

Miller, G.L. (1972). Use of DNS reagent for determination of reducing sugar. Analytical Chemistry, 31, 426-428. https://doi.org/10.1021/ ac60147a030

O'Sullivan, L., Murphy, B., McLoughlin, P., Duggan, P., Lawlor, P.G., Hughes, H. and Gardiner, G.E. (2010). Prebiotic from marine macroalgae for human and animal health applications. Marine Drugs, 8(7), 2038 -2064. https://doi.org/10.3390/md8072038

Rubel, I.A., Perez, E.E., Genovese, D.B. and Manrique, G.D. (2014). In vitro prebiotic activity of inulin-rich carbohydrates extracted from Jerusalem artichoke (Helianthus tuberosus L.) tubers at different storage times by Lactobacillus paracasei. Food Research International, 62, 59-65. https://doi.org/10.1016/ j.foodres.2014.02.024

Saad, N., Delattre, C., Urdaci, M., Schmitter, J.M. and Bressollier, P. (2013). An overview of the last advances in probiotic and prebiotic field. $L W T$ Food Science and Technology, 50(1), 1-16. https:// doi.org/10.1016/j.lwt.2012.05.014

Sakulpong, A., Wongklom, A. and Moonsin, P. (2015). Total phenolics, flavonoids and antioxidant activity of macroalgae fermented with lactic acid bacteria. Journal of Food Science and Agricultural Technology, 1(1), 177-181.

Shalini, R., Abinaja, G., Saranya, P. and Antony, U. (2017). Growth of selected probiotic bacterial strains with fructans from Nendran banana and garlic. $L W T$ Food Science and Technology, 83, 68-78. https:// doi.org/10.1016/j.lwt.2017.03.059

Wongputtisin, P., Ramaraj, R., Unpaprom, Y., Kawaree, R. and Pongtrakul, N. (2015). Raffinose family oligosaccharides in seed of Glycine max cv. Chiang Mai60 and potential source of prebiotic substances. International Journal of Food Science and Technology, 50(8), $1750 \quad-1756 . \quad$ https:// doi.org/10.1111/ijfs. 12842

Yap, W-F., Tay, V., Tan, S-H., Yow, Y-Y. and Chew, J. (2019). Decoding antioxidant and antibacterial potential of Malaysian green seaweeds: Caulerpa racemosa and Caulerpa lentillifera. Antibioitcs, 8(3), 152. https://doi.org/10.3390/antibiotics8030152 